\title{
Wacker Builds Dispersions Plant in Korea
}

In order to meet the growing demand for high-quality VAE dispersions, especially in South East Asia, Wacker Chemie is currently building a new production plant at its Ulsan site in South Korea. The expansion projects in Korea and China will double the company's VAE capacity in this region.

W acker already produces vinyl acetate-ethylene copolymer dispersions marketed under its Vinnapas brand at Ulsan for use as binders in the adhesives industry. The company sees the construction of a second reactor line with an additional 40,000 metric tons of annual capacity for applications in the paints and coatings, construction, nonwoven, paper and carpet industries to be essential for reliably and sustainably meeting the market growth that industry experts anticipate in the region. An investment of around 10 million euros has been budgeted for the expansion project.

"Our new production facility for VAE dispersions at Ulsan represents a key step in our global growth strategy," explained Auguste Willems, Executive Board member of Wacker Chemie AG. He added that demand for top-quality VAE dispersions, especially for those used in formulating more environmentally friendly products featuring low emissions, would continue growing in the coming years. "That was why we also began this spring expanding annual VAE capacity at our Chinese site in Nanjing, where we are adding 60,000 metric tons. The new capacity is expected to come on stream by mid-2013. Our expansion projects in South Korea and China will double our VAE capacity in the region, and thus help us consolidate our already strong position as a globally leading producer of VAE dispersions."

Han-Hyung Cho, head of Wacker Chemicals Korea, stressed the importance of the new plant for Asian markets: "The additional capacity will enable us to continue supplying high-quality, locally manufactured products and solutions to our customers in the region and meet their special requirements in a targeted manner." Using the Ulsan site's existing infrastructure, he added, would enable favourable manufacturing costs and lead to synergy effects in the areas of transportation and logi-

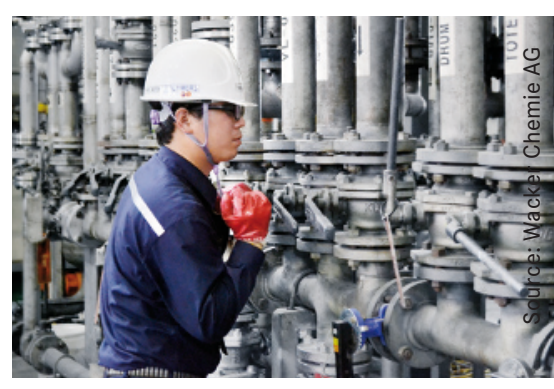

An employee supervises the production processes in the control room of the VAE plant in Ulsan. Wacker already produces VAE dispersions in South Korea for the adhesives industry.

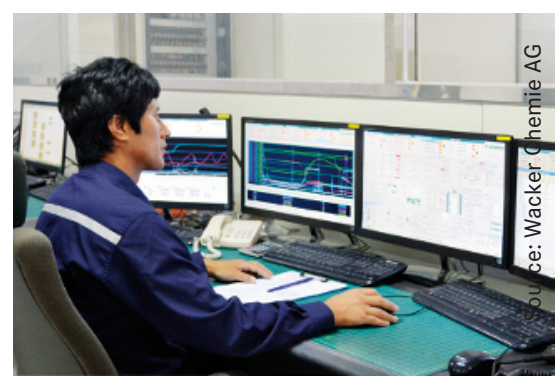

Tank and filling warehouse in Ulsan

stics. The expanded site in Ulsan will be one of the biggest of its kind in South Korea.

\section{Harmonised European Method for Testing VOC Emissions}

The Eurofins Product Testing A/S laboratory has announced that the harmonised European testing method for VOC emissions has been approved by the relevant working group of the European Committee for Standardisation (CEN) as part of the European Construction Products Regulation (CPR).

A ccording to the schedule, VOC tests for CE marking will be carried out using this method in between one and two years' time. In addition, it is likely that in future a variety of national quality labels for low-emission products will be awarded on the basis of corresponding harmonised test methods.

Emission tests of items such as construction products, furniture and de- tachable parts from vehicle interiors are carried out to ensure that the products comply with legal requirements or with the standards for voluntary eco-labels. However, the tests have not always been fully reproducible from one laboratory to another.

In order to improve the quality of the processes, the standard that has now been adopted specifies, among other things, precise test chamber parameters and permitted deviations. The most important change is that the emissions for all test results are calculated on the basis of a European reference procedure.

Eurofins is offering a series of seminars on this subject.

For more information, please visit: www.eurofins.com/galten 